\title{
COMPARISON OF THE EFFECTS OF TOFACITINIB AND ADALIMUMAB ON TRANSCOLONOSCOPIC PH AND CALPROTECTIN LEVELS IN PATIENTS WITH ULCERATIVE COLITIS
}

DOI: 10.36740/WLek202003105

\author{
Antonina V. Varvarynets, Ksenija I. Chubirko, Ivan V. Chopey, Yana Y. Hnepa, Artur V. Kurakh \\ SHEI «UZHHOROD NATIONAL UNIVERSITY», UZHHOROD, UKRAINE
}

\begin{abstract}
The aim: To investigate the transcolonoscopic pH-metry and calprotectin in patients with ulcerative colitis.

Materials and methods: the research included 110 patients both male and female between the ages of 18 to 75 years old, who were treated for UC of medium and severe activity, in active phase. All patients were divided into 3 groups. The first group received standard therapy ( $S T ; n=50$ ), the second group received adalimumab (ADA; $n=32$ ), and the third group was treated with tofacitinib (TOF; $n=28$ ). The control group consisted of healthy individuals between the ages of 18 and 65 years old.

Results: UC patients had lower pH levels in all sections of the large intestine, compared to the control group $(p<0,05)$. Calprotectin level is a better predictor of the course of the disease.

Conclusions:Tofacitinib, compared to adalimumab and budesonide, has better influence on clinical, endoscopic and laboratory parameters of UC.
\end{abstract}

KEY WORDS: ulcerative colitis, calprotectin, pH-metry

Wiad Lek. 2020;73(3):441-443

\section{INTRODUCTION}

Ulcerative colitis (UC) is a multifactorial disease, which manifests in a chronic, recurrent bowel inflammation. Its course is undulating and continuous. The etiology is still unclear, but it was proven, that there is a complex interaction between genetic, microbiologic and external factors. $[1,2]$

Endoscopic and morphologic methods are the main diagnostic methods in UC, which enable us to assess the activity of the process and its prevalence. But even these methods aren't accurate enough. That's why physicians are in dire need of a method which would be accurate, simple and available, so they may quickly and precisely assess the state of the digestive system $[3,4]$. Latest researches have a goal of developing new diagnostic and treatment methods for chronic IBD, to achieve a clinical and endoscopic remission, prevent relapse and increase the quality of life.

Problems with $\mathrm{pH}$ measurement in the large intestine have great theoretic and clinical value, because $\mathrm{pH}$ levels facilitates the diagnostic process and the course of treatment. In UC most of the mucous membrane is intact. Absorption and secretion are altered, as well as electrolite and water exchange between colonocytes and contents of the intestine. Colonocytes secrete less bicarbonate, which results in lesser absorption of acidic compounds. In addition, colitis increases the intensity of fermentation processes, which is also accompanied by the accumulation of a large number of short-chain fatty acids in the gut that acidify the environment. Also, UC increases fermentation, leading to accumulation of short-chain fatty acids, which lower the $\mathrm{pH}$ even further. Lactic acid production is increased in severe UC. $[5,6]$ Non the less, large intestine $\mathrm{pH}$ mesurment is a difficult process in most clinical situations, because of its complexity, bulkiness, inaccuracy and limitation.

Nowadays the easiest and most informative method for measuring large intestine $\mathrm{pH}$ is via $\mathrm{pH}$-probe during fibrocolonoscopy. The potential of diagnostic laboratories has increased in recent years, due to technological progress. They can detect biomarkers of inflammation not only in serum, but in feces as well.

Calprotectin is one of the markers of neutrophilic inflammation and an indicator of the intensity of the inflammatory process of intestinal inflammation in diseases of the digestive tract. It is a calcium binding protein, with antibacterial and antifungal activity, induces apoptosis in malignant and benign cells. This protein is stable, remains in feces at room temperature up to 7 days, whih makes it an ideal diagnostic marker. $[7,8]$

First research on calprotectin was conducted in Norway in 1997 p. A.G. Roseth et al. Levels of fecal calprotectin were assessed in patients with active UC, inactive $\mathrm{UC}$ and in a control group. The levels were $68,11.5$ and $6 \mathrm{mg} / \mathrm{l} \mathrm{re}-$ spectively. The conclusion was made, that fecal calprotectin may be used as a marker of disease activity. [9]

Fecal calprotectin is a marker of intestinal inflammation and provides the opportunity to noninvasively differentiate between irritated bowel syndrome and IBD, to monitor the course of the disease/treatment of UC. It's a potential 
Table I. pH levels in different sections of the large intestine before and after treatment $(M \pm m)$

\begin{tabular}{cccccc}
\hline Large intestine secrion & & ST & ADA & TOF & Control \\
\hline \multirow{2}{*}{ Rectum } & Before treatment & $7.02 \pm 0.16$ & $7.04 \pm 0.13$ & $7.05 \pm 0.15$ & $7.62 \pm 0.23$ \\
\cline { 2 - 5 } & After treatment & $7.02 \pm 0.14$ & $7.06 \pm 0.12$ & $7.18 \pm 0.12$ & $7.94 \pm 0.08$ \\
\hline \multirow{2}{*}{ Sigmoid } & Before treatment & $6.84 \pm 0.07$ & $6.92 \pm 0.08$ & $7.64 \pm 0.19$ \\
\cline { 2 - 5 } & After treatment & $6.88 \pm 0.08$ & $6.97 \pm 0.07$ & $7.27 \pm 0.10$ & $7.44 \pm 0.17$ \\
\cline { 2 - 5 } Transverse & Before treatment & $7.10 \pm 0.24$ & $7.10 \pm 0.22$ & $7.03 \pm 0.17$ & $7.22 \pm 0.04$ \\
\cline { 2 - 5 } & After treatment & $7.11 \pm 0.04$ & $7.20 \pm 0.06$ & $7.26 \pm 0.16$ \\
\hline \multirow{2}{*}{ Cecum } & Before treatment & $7.01 \pm 0.06$ & $6.98 \pm 0.04$ & $7.01 \pm 0.04$ \\
\cline { 2 - 5 } & After treatment & $7.01 \pm 0.05$ & $7.01 \pm 0.04$ & $7.11 \pm 0.04$ & \\
\hline
\end{tabular}

$\mathrm{p}<0,05$ for all groups, compared to healthy patients and during treatment

screening marker for colorectal neoplastic processes. This marker provides a diagnostic result without using radiologic or endoscopic tests.

The main benefit of fecal calprotectin is its diagnostic value: low levels indicate an absence of organic disease of the intestine, while in active UC the levels are much higher. [10]

\section{THE AIM}

To investigate the transcolonoscopic pH-metry and calprotectin in patients with ulcerative colitis.

\section{MATERIALS AND METHODS}

The research included 110 patients, which were treated for medium and severe UC in active phase in CE "Uzhhorod regional hospital" in 2017-2018. The diagnosis UC was based on clinical, endoscopic and histological findings. The activity of the disease was assessed using the index of clinical activity and the MAYO score (Shroeder KV, 1987). At time of inclusion, the duration of UC was not less than 6 months and the index of pathologic activity was between 6 and 12. Both male and female patients, between the ages of 18 to 75 years old were included. Data was gathered from patients' history records, ambulatory medical records and anamnesis morbi. Patients were divided into 3 groups depending on the treatment received. The first group received standard therapy (ST; $n=50)$, the second group received adalimumab with a starting dose of $160 \mathrm{mg}$ and $80 \mathrm{mg}$ on the second week of treatment, and a supporting dose - 40 mg weekly(ADA; $n=32)$, and the third group was treated with tofacitinib $10 \mathrm{mg}$ b.i.d. (TOF; $\mathrm{n}=28$ ). The control group consisted of 30 healthy individuals between the ages of 18 and 65 years old.

Clinical, instrumental and laboratory tests were performed all of patients. Also calprotectin and $\mathrm{pH}$ levels were measured. Transcolonoscopic $\mathrm{pH}$-metry was performed.

Statistical analysis was conducted using a variational-statistical method. Mean values (M), their standard deviation $(\mathrm{m})$ and confidence intervals were calculated. The probability of differences was estimated by Student's $\mathrm{t}$-test for dependent and independent samples.

\section{RESULTS}

Prior to treatment the endoscopic activity index (EAI) was almost identical and corresponded with medium severity of UC $(9.22 \pm 0,40)$. Statistically significant improvement of the EAI was observed in all four groups after treatment.

Measurement of $\mathrm{pH}$ levels near the mucous membrane of the large intestine in healthy people, showed a tendency toward alkalosis, which increased in the distant segments (7.24 $\pm 0.16 ; 7.42 \pm 0.16 ; 7.62 \pm 0.17 ; 7.62 \pm 0.22$ in the cecum, transverse colon, sigmoid colon and rectum respectively). Such differences in $\mathrm{pH}$ levels throughout the large intestine may be associated with the microbe homeostasis, volatile fatty acid production and the difference in absorption rate in the cecum and rectum, which is much higher in proximal regions of the intestine.

Dynamic changes of transcolonoscopic $\mathrm{pH}$ levels before treatment in ST, ADA and TOF groups showed a statistically significant decrase of those levels in all sections of the large intestine, compared to the control group $(\mathrm{p}<0.05)$. This tendency remained after treatment as well $(\mathrm{p}<0.05)$. This means, that the treatment led to improvement of $\mathrm{pH}$ levels in UC patients, but didn't normalize them, as in healthy patients. (Table 1 ).

Data analysis showed statistically significant differences in $\mathrm{pH}$ levels were found in the sigmoid colon, transverse colon and cecum, when comparing groups before and after treatment (TOF) $(\mathrm{p}<0.05)$.

Fecal calprotectin levels were high in all groups prior to treatment, mean concentration was $466.4 \pm 35.6 \mu \mathrm{g} / \mathrm{g}($ norm $50 \mu \mathrm{g} / \mathrm{g}$ ).

In the I group, which received standard therapy, calprotectin dropped to optimal levels in $26.0 \%(n=13)$ of patients $122.4 \pm 9.1 \mu \mathrm{g} / \mathrm{g}$, in the II group - in $56.3 \%(\mathrm{n}=18)$ of patients mean FC level was $102.6 \pm 10.2 \mu \mathrm{g} / \mathrm{g}$, and in the III group - most of the patients $-71.4 \%(n=20)-$ mean FC level was $96.2 \pm 9.4 \mu \mathrm{g} / \mathrm{g}$. FC levels remained high in all other patients: in the I group - 74.0\% $(\mathrm{n}=37)$ mean FC levels was $252.4 \pm 12.6 \mu \mathrm{g} / \mathrm{g}$, in the II group $-43.7 \%(\mathrm{n}=14)$ mean levels were $212 \pm 8.4 \mu \mathrm{g} / \mathrm{g}$ and in the III group - 28.6 $\%(\mathrm{n}=8)$ it was the lowest $-162 \pm 9.2 \mu \mathrm{g} / \mathrm{g}$. All the patients that with high levels of calprotectin, had a relapse of UC during the next 6 months.

From this data we may conclude, that FC levels a high sensitivity rate for monitoring the course of UC. 
Despite the fact, that $\mathrm{FC}$ levels didn't return to normal in any of the groups $(<50 \mu \mathrm{g} / \mathrm{g})$, the best results were exhibited by the III group of patients, which received tofacitinib.

\section{DISCUSION}

In this research we investigated the $\mathrm{pH}$ levels near the wall of the large intestine and calprotectin levels in UC patients, which received budesonide, adalimumab and tofacitinib. These tests allow us to better determine the state of the intestine and to monitor the course course and treatment of ulcerative colitis.

Coincidentally, the patients that had high levels of calprotectin after treatment, had a relapse of UC in the duration of 6 months. This leads to the conclusion that calprotectin is a more sensitive marker of ulcerative colitis.

Tofacitinib - janus kinase inhibitor, had a greater treatment effect, compared to budesonide and adalimumab.

\section{CONCLUSIONS}

1. Tofacitinib, compared to budesonide and adalimumab, has greater effect on clinical, endoscopic and laboratory signs of UC.

2. In UC patients in the end of the treatment, near wall $\mathrm{pH}$ levels in the large intestine improved slightly. The best improvement was in the III group (TOF).

3. Calprotectin - is a more sensitive marker for diagnosis, differential diagnosis and monitoring the course of ulcerative colitis.

\section{REFERENCES}

1. Feuerstein JD, Cheifetz AS. Ulcerative colitis: epidemiology, diagnosis, and management Mayo Clin Proc. 2014; 89(11):1553-1563.

2. Ye Y, Pang Z, Chen W, Ju S, Zhou C. The epidemiology and risk factors of inflammatory bowel disease. Int I Clin Exp Med 2015; 8: 22529-22542.

3. Noor M, Venrataraman S. Clinical relevance of endoscopic assessment of inflammation in ulcerative colitis: Can endoscopic evaluation predict outcomes? World J Gastroenterol. 2016 Nov 14; 22(42): 9324-9332. doi: 10.3748 /wjg.v22.i42.9324

4. Christensen B, Rubin DT. Understanding endoscopic disease activity in IBD: how to incorporate it into practice. Curr Gastroenterol Rep. 2016;18:5. doi: 10.1007/s11894-015-0477-6.

5. Bernstein CN, Forbes JD. Gut Microbiome in Inflammatory Bowel Disease and Other Chronic Immune-Mediated Inflammatory Diseases. Inflammatory Intestinal Diseases. 2017;2:116-123.
6. Travis SP, Schnell D, Krzeski P et al. Reliability and initial validation of the ulcerative colitis endoscopic index of severity. Gastroenterology. 2013;145:987-995.

7. Kristensen V, Klepp P, Cvancarova M et al. Prediction of endoscopic disease activity in ulcerative colitis by two different assays for fecal calprotectin. J Crohns Colitis 2015;9:164-169.

8. Zittan E, Kelly $O B$, Kirsch R, et al. Low fecal calprotectin correlates with histological remission and mucosal healing in ulcerative colitis and colonic Crohn's disease. Inflamm Bowel Dis. 2016;22:623-630.

9. Roseth A.G., Aadland E., Jahnsen J., Raknerud N. Assessment of disease activity in ulcerative colitis by faecal calprotectin, a novel granulocyte marker protein. Digestion. Digestion 1997;58:176-180.

10. Yamaguchi $S$, Takeuchi Y, Arai $K$ et al. Fecal calprotectin is a clinically relevant biomarker of mucosal healing in patients with quiescent ulcerative colitis. J Gastroenterol Hepatol. 2016;3:93-98.

\section{ORCID and contributionship:}

Antonina V. Varvarynets - 0000-0001-5859-1040 A,DF

Ivan V. Chopey - 0000-0003-4626-0855 $5^{A, F}$

Ksenija I. Chubirko - 0000-0002-4379-0538 A, B

Yana Y. Hnepa - 0000-0002-0276-1466 ${ }^{B C E}$

Artur V. Kurakh - 0000-0003-2793-5044 ${ }^{\text {EC }}$

\section{Conflict of interest:}

The Authors declare no conflict of interest.

\section{CORRESPONDING AUTHOR Antonina V. Varvarynets}

71 Minayska Str., 88000, Uzhhorod, Ukraine

e-mail: tonichka8387@gmail.com

tel: +380679810601

Received: 17.01 .2020

Accepted: 05.03.2020

A - Work concept and design, B - Data collection and analysis, C - Responsibility for statistical analysis, $\mathbf{D}$-Writing the article, $\mathbf{E}$-Critical review, $\mathbf{F}$ - Final approval of the article 